\title{
Evaluating the LCA of a Building with Close Embodied Energy Which Has Different Functions
}

\author{
Mustafa Erkan Karaguler ${ }^{1}$ and Pooya Pakmehr ${ }^{2}$ \\ 1. Department of Architecture, Istanbul Technical University, Istanbul 34437, Turkey \\ 2. Department of Engineering and Technology, Istanbul Technical University, Istanbul 34437, Turkey
}

\begin{abstract}
Annual energy consumption and annual Global Warming Potential (GWP) decreases with the improving of the energy performance of the facade, whereas the embodied energy and embodied GWP increases due to the extra material and products applied. This study analyses the relation between the embodied energy and the energy consumption of a house during the life span of the buildings, and the results represented separately in tables and figures. The study uses Life Cycle Assessment (LCA) framework as a tool to conduct a partial LCA, from cradle to site of the construction and energy consumption during usage phase of the buildings with three different wall types through 50 years usage phase. According to this study, laminated timber and aerated concrete are better choices than cast concrete for both types of buildings because of lower density and lower U value.
\end{abstract}

Key words: Life cycle assessment, embodied energy, operating energy.

\section{Introduction}

Turkey's importance in the energy markets is growing, both as a regional energy transit hub and as a growing consumer. Turkey's energy has increased rapidly over the last few years and will likely continue to grow in the future. Turkey imports nearly all of its oil supplies. Turkey is increasingly dependent on natural gas imports as its domestic consumption keeps rising each year. Natural gas is used domestically mainly in the electric power sector [1]. Hence, mandatory using LCA for all types of buildings can reduce a country's demand and affiliation to other states.

Studies assuming that operational energy contribute $52 \%$ to $82 \%$ of the total life cycle energy consumption during 40 to 50 year lifespan. In addition, embodied energy consumes the rest of the LCA behind the little impact of demolition and transportation [2]. This is clear that with the increasing life span of a building, the significance of the embodied energy becomes inconsiderable [3].

Corresponding author: Pooya Pakmehr, master, main research field: life cycle assessment of the building.
From life cycle point of view, there is a limit to the thickness of insulation which can be applied on external walls [4]. Effort should be paid to the reduction of the energy consumption during the usage phase, as this stage still has the largest potential for improvement, both for new and old buildings [5]. So, maybe using an innovative material, such as phase change materials in the building, can be a real solution for this.

\section{Methodology and Simulation}

Values of embodied energy and amount of gas emission from each database are different from one country to another because of energy production, fuel type, transformation process, the technology of the system and how these factors change over time [6]. Nevertheless, Inventory of Carbon and Energy (ICE) database are used for carbon footprint studies. The aim of this study is comparing Life Cycle performance of different wall types, so it does not affect the results.

Fig. 1 expresses briefly the life cycle steps from cradle to grave. Construction machinery consumes lots of energy through extracting the raw materials. Transporting the raw material from mine to the factory 


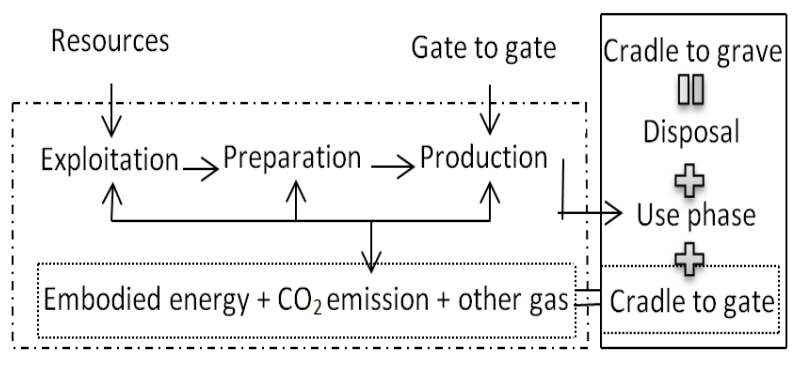

Fig. 1 Cradle to grave process.

releases lots of $\mathrm{CO}_{2}$ to the environment. Raw material should be prepared to use as the construction building material, and for this purpose, facility consumes lots of energy to build the material. Through this process, lots of $\mathrm{CO}_{2}$ and energy release. All these steps can be called as cradle to gate, and the data about all of these steps were gathered from databases which are mentioned before [7]. Materials must be distributed from factory to the distributors or construction site. During transportation, lots of $\mathrm{CO}_{2}$ were released to the environment.

Use phase starts with the occupants and their demand for electricity, heating and cooling, which is calculated with Design Builder simulation software. The last stage of the LCA according to ISO 14040 is disposal and consequently the emission parts. On-site construction and demolition contribute almost $1 \%$ of LCA at the end of its service life, which are both ignored through this study [8]. This study does not calculate the effect of other gas emissions and disposal.

\section{Condition}

Case studies are related to a house with three levels that located in Istanbul, Turkey. Three story house with $152 \mathrm{~m}^{2}$ occupied floor area that occupants stay 12 hours a day at home except holidays. The object studied is an external wall of the building with the latitude of $40.97^{\circ}$ and longitude of $28.82^{\circ}$.

This study uses three different wall types with 3 different $U$ values and thickness of almost 0.23 meters. According to TS 825 (2008), the standard wall for Istanbul should have $0.6 \mathrm{~W} / \mathrm{m}^{2} \cdot \mathrm{K}$ and $0.4 \mathrm{~W} / \mathrm{m}^{2} \cdot \mathrm{K}$ for flat roof and $0.6 \mathrm{~W} / \mathrm{m}^{2} \cdot \mathrm{K}$ for the ground floor. For this study, three different wall types were considered with various $U$ values and different materials. The $U$ value for all glazing types set to be $2.4 \mathrm{~W} / \mathrm{m}^{2} \cdot \mathrm{K}$. Tables $1-3$ show the detailed feature of each wall type, which stucco is the inner face of the wall and marble tile, laminated timber and external rendering are the outerlayer of the wall.

The Life Cycle Analysis (LCA) recommends the use of Phase Change Material (PCM) in buildings [9]. There are different ways to use aerogels for insulation applications. Properties of an aerogel product strongly depend on the preparation. In thermal insulation, aerogel products show outstanding performance compared to traditional materials [10]. Using aerogel between two concrete should be valuable, so the first wall consists of two cast concrete with aerogel between them. Timber is the superior material for structural and cladding systems, so the second wall is designed to include timber products [3]. To challenge the issue, the third wall is chosen to design with aerated concrete and EPS (expanded polystyrene).

Table 1 Wall type 1.

\begin{tabular}{lll}
\hline Material & Thickness $(\mathrm{m})$ & $\mathrm{U}$-value $\left(\mathrm{W} / \mathrm{m}^{2} \cdot \mathrm{K}\right)$ \\
\hline Stucco & 0.019 & \\
Cast concrete & 0.08 & \\
Aerogel & 0.02 & 0.559 \\
Cast concrete & 0.08 & \\
Marble tile & 0.03 & \\
\hline
\end{tabular}

Table 2 Wall type 2.

\begin{tabular}{lll}
\hline Material & Thickness $(\mathrm{m})$ & $\mathrm{U}$-value $\left(\mathrm{W} / \mathrm{m}^{2} \cdot \mathrm{K}\right)$ \\
\hline Stucco & 0.019 & \\
Softwood & 0.04 & 0.346 \\
Rock wool & 0.08 & \\
laminated timber & 0.09 & \\
\hline
\end{tabular}

Table 3 Wall type 3.

\begin{tabular}{lll}
\hline Material & Thickness $(\mathrm{m})$ & $\mathrm{U}$-value $\left(\mathrm{W} / \mathrm{m}^{2} \cdot \mathrm{K}\right)$ \\
\hline Stucco & 0.019 & \\
Aerated concrete & 0.17 & 0.6 \\
EPS & 0.013 & \\
External rendering & 0.019 & \\
\hline
\end{tabular}




\section{Evaluating Embodied Energy}

As shown in Fig. 2, the contribution of each material with embodied energy in the wall is presented. The quantity of stucco for all wall types is the constant amount, so the EBE will be the same. Wall type 3 is with aerated concrete and EPS have the minimum EBE among others while the second wall with soft wood, rock wool and laminated timber with total 246,049 MJ have amaximum of that. Dark blue, light green and orange colour show the amount of insulation on each wall. Aerogel insulation represents almost 19\% of wholly embodied energy in the wall type one while the rock wool depicts $15 \%$ effects on wall type 2, and EPS in wall 3 just include $9 \%$ of the whole wall since a little amount of that are used. Besides, in wall three, aerated concrete was used as insulation. As Fig. 2 shows, marble tile has $81,398 \mathrm{MJ}$ embodied energy, which is more than $39 \%$ of the whole EBE of wall type 1. Laminated timber with 147,711 MJ embodied energy includes almost $60 \%$ of that of wall type 2 .

Each material in a wall may be a better choice to compare embodied energy because most of the materials have limitation about their thicknesses and we do not allow using thinner than that amount. Therefore, if the wall will be designed to be thinner, the embodied energy of the whole wall will be reduced.

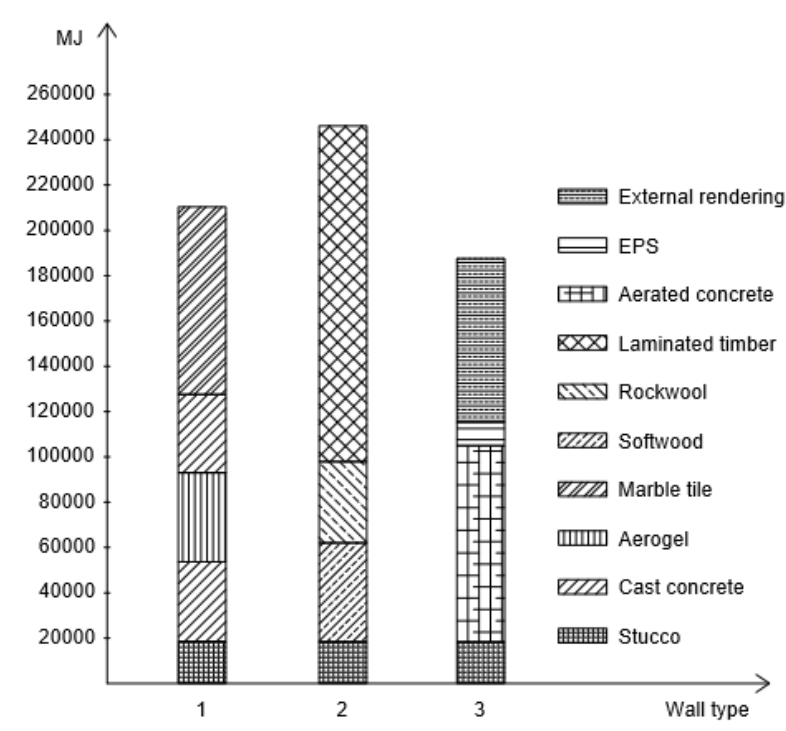

Fig. 2 Embodied energy of each wall.

\section{Greenhouse Gas Emission}

In terms of embodied $\mathrm{CO}_{2}$, all three types of walls have impacts between 11,000 and $19,000 \mathrm{Kg} \mathrm{CO} / \mathrm{Kg}$. Cast concrete in the first wall contains $53 \%$ of total $\mathrm{CO}_{2}$ emissions. The laminated timber in the second wall with $48 \%$ effect and aerated concrete in the third wall with $54 \%$ footprint are materials in each wall that have maximum impacts. Among these insulations, aerogel with 3,078 and rock wool with 2,569 $\mathrm{Kg}$ $\mathrm{CO}_{2} / \mathrm{Kg}$ have close $\mathrm{CO}_{2}$ emissions, despite being different in the volume amount $\left(24 \mathrm{~m}^{3}\right.$ for wool and 6 $\mathrm{m}^{3}$ for aerogel).

As we can distinguish from Fig. 3, wall type 1 with total $18,869 \mathrm{Kg} \mathrm{CO}_{2}$ has maximum impact, while the wall type 2 has $38 \%$ less embodied carbon than the first wall, and wall type 3 has $27 \%$ less embodied carbon. Several observations can be achieved from Fig. 3, since the thickness, density and the quantity of material have a significant role in evaluating the footprint of each building.

\section{Transportation}

This study attempts to calculate the $\mathrm{CO}_{2}$ emission during transportation with different vehicles such as, truck and ship. Most of the information about the embodied energy and embodied carbon of materials was derived from Sustainable Energy research team of BATH University [11]. Gabi simulation was used to

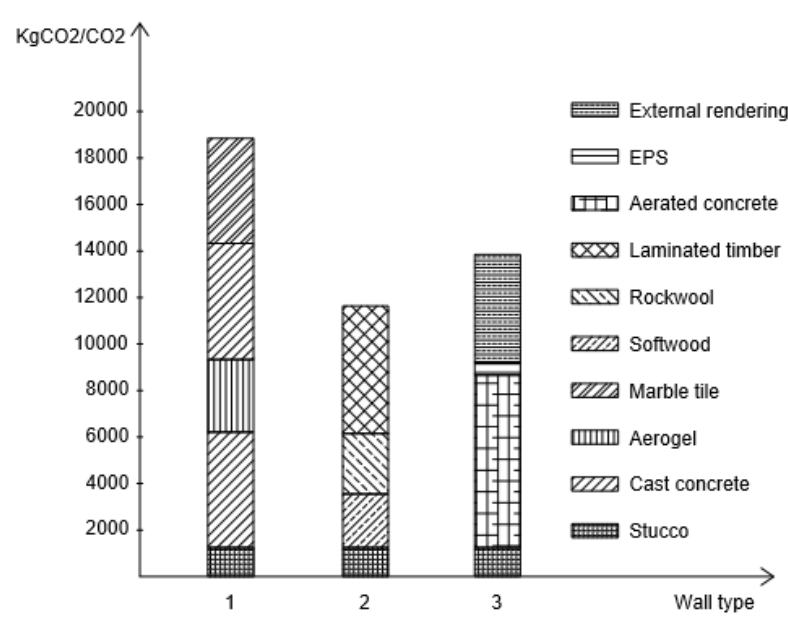

Fig. 3 Embodied carbon of each wall. 
Table 4 Features of theused material [11].

\begin{tabular}{|c|c|c|c|c|c|}
\hline & Material & Density $\left(\mathrm{Kg} / \mathrm{m}^{3}\right)$ & Material quantity & $\begin{array}{l}\text { Embodied energy } \\
(\mathrm{MJ} / \mathrm{Kg})\end{array}$ & $\begin{array}{l}\text { Embodied carbon } \\
\left(\mathrm{Kg} \mathrm{CO}_{2} / \mathrm{Kg}\right)\end{array}$ \\
\hline \multirow{4}{*}{ Wall type 1} & Stucco & 1,800 & 5.82 & 1.8 & 0.12 \\
\hline & Cast concrete & 2,000 & 46.6 & 0.75 & 0.107 \\
\hline & Aerogel & 120 & 6.11 & 53 & 4.2 \\
\hline & Marble tile & 2,800 & 8.73 & 3.33 & 0.187 \\
\hline \multirow{4}{*}{ Wall type 2} & Stucco & 1,800 & 5.82 & 1.8 & 0.12 \\
\hline & Softwood & 510 & 11.64 & 7.4 & 0.39 \\
\hline & Rock wool & 92 & 23.28 & 16.6 & 1.2 \\
\hline & Laminatedtimber & 470 & 26.19 & 12 & 0.45 \\
\hline \multirow{4}{*}{ Wall type 3} & Stucco & 1,800 & 5.82 & 1.8 & 0.12 \\
\hline & Aerated concrete & 500 & 49.47 & 3.5 & 0.3 \\
\hline & EPS & 25 & 3.78 & 109.2 & 4.39 \\
\hline & External rendering & 1,300 & 5.52 & 10 & 0.65 \\
\hline
\end{tabular}

Table $5 \mathrm{CO}_{2}$ emission during transportation.

\begin{tabular}{lll}
\hline Material & Wall weight $(\mathrm{Kg})$ & $\mathrm{CO}_{2}$ emission $(\mathrm{Kg})$ \\
\hline 1 & 128,773 & 11,500 \\
2 & 30,862 & 2,760 \\
3 & 42,492 & 3,800 \\
\hline
\end{tabular}

calculate the $\mathrm{CO}_{2}$ emission during transportation. Inputs for this software include distance and material weight while the total volume of the walls is almost 67 $\mathrm{m}^{3}$. From Table 5, wall type 1 with total $128,773 \mathrm{Kg}$ has the maximum amount of $\mathrm{CO}_{2}$ emission, while wall type 2 with $30,862 \mathrm{Kg}$ is the lowest. Therefore, the wall with the utmost weight has higher $\mathrm{CO}_{2}$ emission during transportation.

Whole $\mathrm{CO}_{2}$ emission through exploiting the material to the site is gathered in Fig. 4. Wall type 2 have minimum footprint while wall type 1 has maximum effect on the environment.

From the Fig. 4, it is distinguishable that for wall type $1, \mathrm{CO}_{2}$ emission during transportation increases the footprint almost $61 \%$ while this percentage for light materials is approximately $22 \%$. Therefore, transporting heavy materials may increase the $\mathrm{CO}_{2}$ emission more than $60 \%$ of the whole embodied carbon of the building.

\section{Operating Energy}

The operation phase includes energy for space heating, cooling, and ventilation, appliances, miscellaneous, catering and lighting. The hot water demand and electricity consumption largely depend on the users, since the building construction has minimum impact on the energy demand for hot water and household electricity. These requirements were regulated for all buildings using Turkish Standard Institution [12, 13].

Home electricity and lighting for all walls are the same, since changing the wall type do not affect them. Home heating for both of the wall one and wall three are the same because they have close U value, whereas building with laminated timber wall has minimum heating consumption.

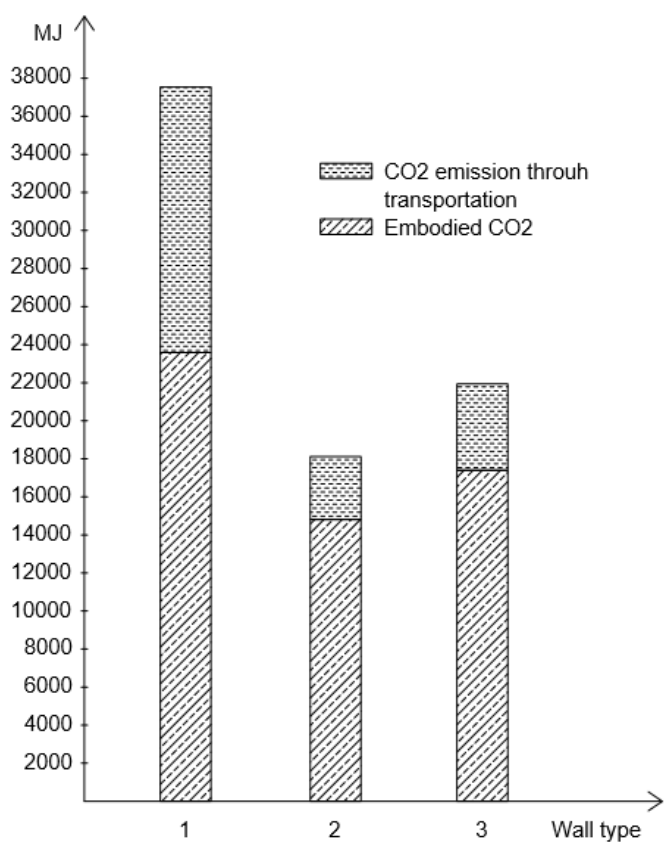

Fig. 4 Total $\mathrm{CO}_{2}$ emission from cradle to site. 


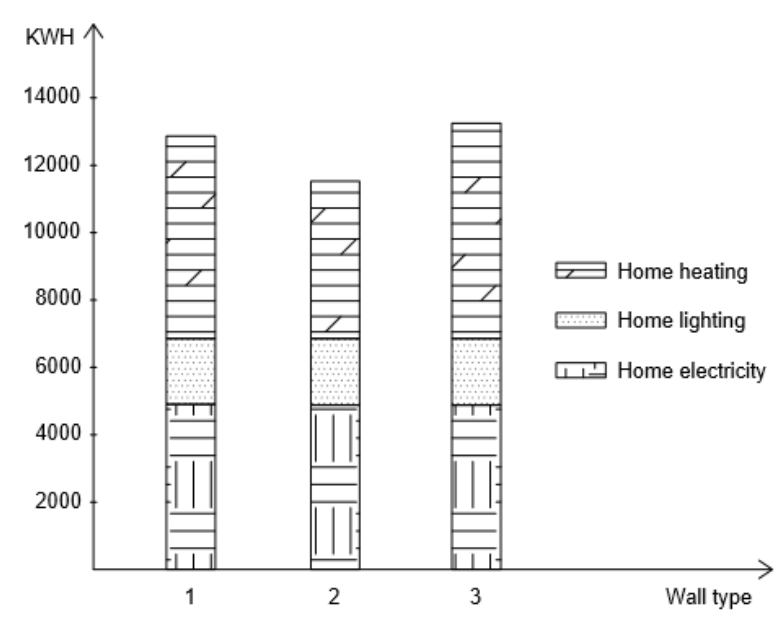

Fig. 5 Operating energy of home.

Fig. 5 shows the distribution of different operating energies in the building. Wall type 2 consumes less energy because its U-value is less than the other two walls. Wall type 3 consumes a little bit more energy than wall type one, and this is because of the small difference between $U$ values of them.

\section{LCA in Building Scale}

Despite climate and other differences, the study of some residential and non-residential cases from nine countries revealed a linear relation between operating and the total amount of energy [6]. Fig. 6 shows the life cycle energy of two buildings with 3 wall types in a home over $5,10,15 \ldots$, and 50 years. It includes embodied energy of the whole external façade at the end of construction, embodied carbon from cradle to gate, and the operating energy. This amount will increase gradually during usage phase of the building, since each year buildings consume a high quantity of energy to prepare comfort condition for occupants.

Fig. 6 consists of triple lines which relate to the house with three different wall types. LCA amounts increase annually for each year the building consumes some energy. It is obvious that due to aging, defects and material obsolescence, the performance of all walls will be reduced, but as this fact occurs for all walls, it does not change the results much more.

In construction part, home with wall type 1 has the highest life cycle among others. The third wall type has the minimum life cycle assessment. During usage phase, building with wall type 1 and 3 consumes more operating energy. Yearly energy consumption adds up to the previous year and through each 5-year, the total amount rolled in Fig. 6.

Wall type one with higher embodied energy, higher embodied $\mathrm{CO}_{2}$ and mean $\mathrm{U}$ value is pioneer in LCA for all 50 years. Comparing wall type two and three at each triple shows that the wall type 2 has more embodied energy and embodied carbon than wall type 3 while it has less U value. After 10 years, LCA for all wall types becomes almost the same and after 15 years buildings

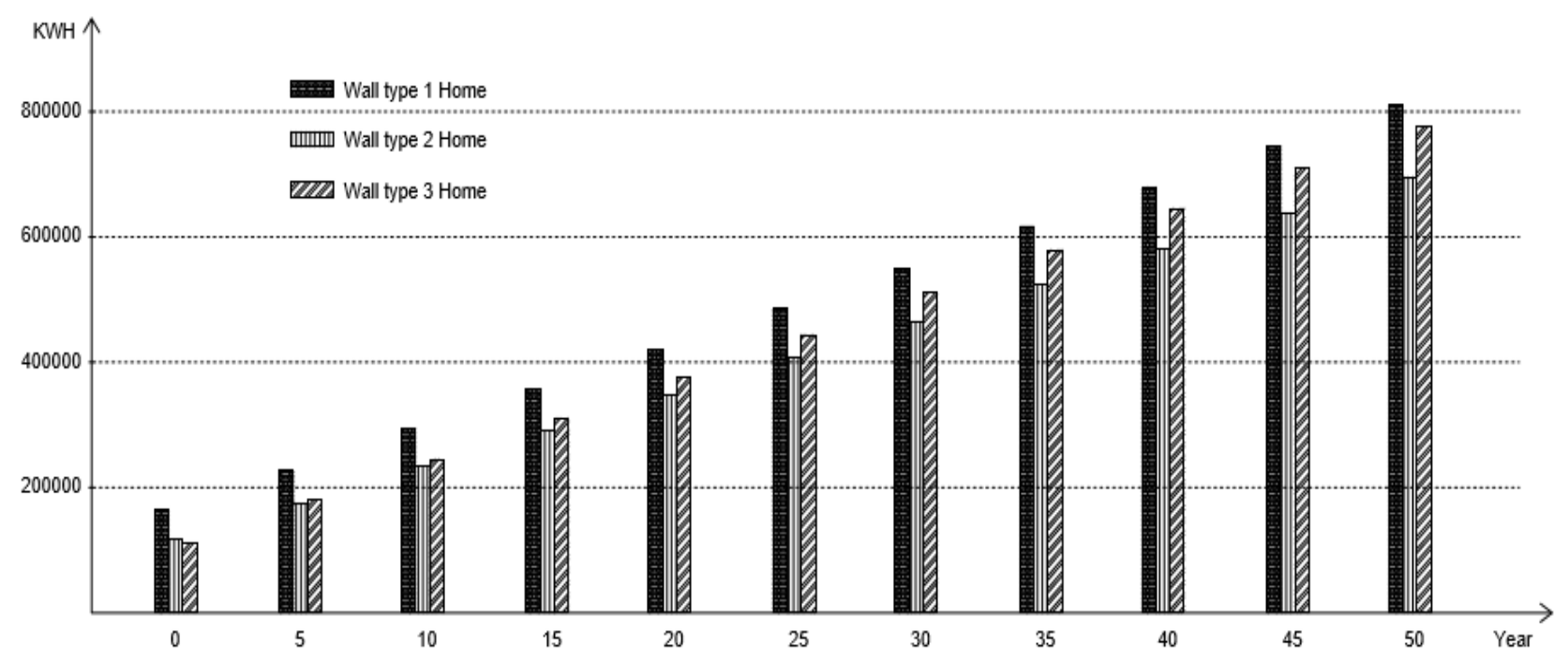

Fig. 6 LCA of two building during 50 years life span. 
with wall type 1 and 3 passes wall type 2. During 50 years usage phase, LCA of building with wall type 3 become closer to the building with wall type 1 .

From Figs. 4 and 6, we can conclude that second wall in every building is the better choice albeit the building should be used more than 10 years even if it has high embodied energy. Moreover, this type of wall has minimum impact on the environment because of its lower weight. Also, it releases a minimum amount of $\mathrm{CO}_{2}$ through transportation.

\section{Conclusions}

The construction industry uses vast quantities of raw materials that also have a high amount of energy consumption. Choosing materials with high embodied energy cause not only a high level of energy consumption in the building production stage but also determines future energy consumption in order to fulfil heating, cooling, ventilation and air conditioning demand [14].

Therefore, outcomes of this paper can be summarized as:

Thickness, quantity and density of each material play a significant role in the embodied energy of a wall. Laminated timber with embodied energy of $12 \mathrm{MJ} / \mathrm{Kg}$ and density of 470 is tolerable among the other materials of Table 4. In the time, using a high amount of laminated timber in wall type 2 caused a significant amount of embodied energy among other walls.

Insulation materials at each wall have the highest embodied energy and embodied carbon, so finding the optimum amount of insulation in each wall helps to reduce the $\mathrm{EBE}$ and $\mathrm{CO}_{2}$ emission.

The $U$ value for wall type 2 is less than that for other two walls, accordingly operating energy consumption by the building with wall type 1 and 3 will be more than the second wall, and this variation will gradually increase during the usage phase.

Building with laminated timber and aerated concrete is superior to the cast concrete. Moreover, if we do not intend to substitute the second wall material before 10 years, laminated timber with soft wood and rock wool should be the right choice.

Even using aerogel between layers of cast concrete does not a good solution for building industry, because $\mathrm{CO}_{2}$ emission of such wall is high.

Although laminated timber is one of the privileged materials, using a thick layer of that in façade flourishes the embodied energy and using a thin layer of that may disturb the performance of the façade.

For most of the buildings around the world with a similar climate to Istanbul, those made with aerated concrete and EPS are preferable to cast concrete and aerogel.

Different wall types have different embodied energies which are between $25 \%$ and $40 \%$ of its operating energy over 25 years period while this amount reduces over 50 years lifespan of the building. For this home, the consumption from cradle to the site of wall type one is $20 \%$ of the whole LCA through 50 years. This amount for wall type 2 is $17 \%$ and for wall type 3 is $14 \%$.

With the reducing operational energy, the impacts of embodied energy increases [15]. Rarely the building demolishes before the end of its life, unless, natural disasters such as earthquake does not happen. Therefore, evaluating the life span of each wall will help us to decide more confidently on the performance of that.

\section{References}

[1] EIA. 2013. "Turkey Country Analysis Brief." U.S. Energy Information Administration. Accessed November 20, 2013. http://www.eia.gov/countries.

[2] Adalberth, K. 1997. "Energy Use during the Life Cycle of Buildings: a Method." Building and Environment 32 (4): $317-320$

[3] Thiel, C. L., Campion, N., Landis, A. E., Jones, A. K., Schaefer. L. A., and Bilec, M. M. 2013. "A Materials Life Cycle Assessment of a Net-zero Energy Building." Energies 6 (2): 1125-1141.

[4] Ramesh, T., Prakash, R., and Shukla, K. K. 2010. "Life Cycle Analysis of Building: an Overview." Energy and Buildings 42 (10): 1592-1600.

[5] Verbeeck, G., and Hens, H. 2010. "Life Cycle Inventory 
of Buildings: A Contribution Analysis.” Building and Environment 45 (4): 964-967.

[6] Sartori, I., and Hestnes, A. 2007. "Energy Use in the Life Cycle of Conventional and Low-energy Buildings: A Review Article." Energy and Buildings 39 (3): 249-257.

[7] Menzies, G. F. 2011. "Embodied Energy Considerations for Existing Buildings." Historic Scotland Technical Paper 13.

[8] Ramesh, T., Prakash, R., and Shukla, K. K. 2012. "Life-cycle Energy Analysis of a Residential Building with Different Envelopes and Climates in the Indian Context." Applied Energy 89 (1): 193-202.

[9] Cabeza, L. F., Barreneche, C., Miró, L., Morera, J. M., Bartolí, E., and Fernández, A. L. 2013. "Low Carbon and Low Embodied Energy Materials in Building: A Review." Renewable and Sustainable Energy Reviews 23: 536-542.

[10] Rovers, R., Kimman, J., and Rovesloot, C. 2010. Towards 0-Impact Building and Built Environment. Amsterdam: Techne Press.
[11] Hammond, G., and Jones, C. 2008. Inventory of Carbon and Energy: ICE. Bath: Sustainable Energy Research Team, Department of Mechanical Engineering, University of Bath.

[12] Turkish Standard. 2008. Turkish Standard Regulation on the Energy Performance of Buildings. No: 27075.

[13] Turkish Standard. 2008. Thermal Insulation Requirements for Buildings. No: 825.

[14] Bribian, I. Z., Capilla, A.V., and Uson, A. A. 2011. "Life Cycle Assessment of Building Materials: Acomparative Analysis of Energy and Environmental Impacts and Evaluation of the Eco-efficiency Improvement Potential." Building and Environment 46 (5): 1133-1140.

[15] Moncaster, A. M., and Symons, K. E. 2013. "A Method and Tool for 'Cradle to Grave' Embodied Carbon and Energy Impacts of UK Buildings in Compliance with the New Tc350 Standards." Energy and Buildings 66: 514-523. 